\title{
Nondestructive Bolt Preload Measurement
}

\author{
By Péter Horváth ${ }^{*}$ \\ Péter Tóth ${ }^{\dagger}$
}

\begin{abstract}
Bolts are very important elements of machines and structures. The usual torque wrench technique guarantees only the torque applied, but the real axial load remains unknown because of friction among bolt threads and between the bolt head and the washer. To make the situation more difficult, the parts of structures prevent direct measurement of axial load, consequently threaded fasteners are usually over-sized for safety reasons. The known nondestructive ultrasonic and electromagnetic acoustic resonance methods have many error factors. This paper proposes a new nondestructive measuring method that relies on bolt head face deformation due to axial load. In this paper the deflection of a M12 bolt head is studied by means of FEA method as well as surface profile and Eddy-current measurements. Results of all methods agreed well, proving that bolt head deformation can be applied in practice as an indication means of bolt load.
\end{abstract}

Keywords: Bolt, Eddy-current, Load, Measurement, Nondestructive.

\section{Introduction}

Most machines and structures contain hundreds of bolts holding machine parts in place. Some of these bolts are critical to the continued secure operation of the equipment and the safety of the workers that operate them. Should these critical bolts fail, it can lead to equipment damage, injury of personnel, and even loss of life. To avoid these undesirable events bolt tension should be properly created. To achieve the desired bolt preload you can apply several methods such as torque control, torque-angle control, yield control, bolt stretch method and use of tension indicating methods. Choosing whichever, you cannot be absolutely certain that the desired tension will be created, because there can be as many as 200 factors that affect the tension when tightening (Shoberg, 2017). The highest problem is caused by friction. The effect of factors influencing needed torque and emergent bolt preload can be understood if summarizing the zones of tightening process. The first one is rundown that takes place before the bolt head or nut contacts the bearing surfaces. Torque is needed to compensate resistance of outof-tolerance threads, deformation of threads and foreign material in the threads. The second zone is the alignment phase, when all parts of joint are drawn into alignment that needs additional torque. The main cause of misalignment is the initially non-parallelism of contacting surfaces. The third phase is the elastic clamping zone wherein the torque and angle of rotation are proportional to each other, forming a constant slope torque-angle curve. The fourth region is the post yield zone with changing slope curve due to yielding of the treads and gaskets. When applying the most popular torque control method to fasten a bolt,

*Associate Professor, Széchenyi University, Hungary.

'Developer Engineer, EDAG Hungary Kft, Hungary. 
the theoretically necessary torque to tighten the bolt to the needed preload can be calculated with simple expressions, but the reliability of result depends highly on the friction even if rundown and misalignment effects are neglected. As for the effect of friction, the applied torque is absorbed by underhead friction (about $50 \%$ ), thread friction (about 40\%) and only the remaining 10\% develops the clamping force therefore 5\% increase in friction coefficient can reduce bolt load by half (Bolt Science, 2017). Even the effect of friction coefficient scatter can be reduced by the use of friction stabilizers, which are coated onto bolts, the problem remains. A better tightening method is torque-angle control, when a predetermined angle of turn is applied after a specific "threshold" torque level is reached (Fukuoka and Takaki, 2004; Göran, 2003). The scatter of bolt preload will be much less than with tightening with torque control method due to the less yield stress tolerance. But the main disadvantage of this method is the necessity of accurate determination of the angle of turn. A more sophisticated method is yield controlled tightening that is used in critical applications such as connecting rod bolts and cylinder head bolts. A sensitive sensor system detects rapidly both the torque and the angle of rotation simultaneously. The change of slope of the torque-angle curve indicates reaching the yield point of the bolt material. Friction scatter may result in a small degree of preload scatter, since equivalent stress depends on the combination of tensile and torsion stresses, an increased friction leads to lower preload due to a lower direct stress. Several bolt stretch methods are also known, for example application of shape memory alloy (SMA) actuators (Hesse et al., 2004), but they are not widely used.

It is to be noted, that even in case when preload has been set properly, it is to be expected that some of the original preload is lost over time for the reason that components of joint relax and move differently. The main reasons for this phenomenon are embedment relaxation, gasket and bolt creep, vibration, differential thermal expansion and elastic interaction in the joint. When a new bolt is tightened, the components of joint contact on tiny spotsthat will be overloaded. At last these spots will yield that causes bolt relaxation. According to estimations about 5\% preload can be lost. In many cases, gaskets are incorporated in bolted joints that are designed to flow into crevices of the surfaces. At high loads gaskets creep, causing the flanges to come closer to each other, resulting preload loss. Another mechanism may cause preload loss on flanged joints (Sawa et al., 2009). As usual, bolts are tightened using a cross-pattern. When the first bolt is tightened, the flange near the bolt is compressed. Tightening the next bolt near the previously tightened one, the flange is further compressed. This causes the previously tightened bolt to relax a bit, that leads to some loss of preload. Thermal effects may be dangerous as well. Most materials expand as temperature rises. As flanges and gaskets of a pipe are closer to the hot gas of fluid than bolts, they expand faster than bolts, causing increased tension is the bolts. Consequently, gaskets will be compressed further. When the assembly cools down, members of the joint return to their original size except for the gasket, because it is not fully elastic. This change of gasket thickness will cause reduced bolt preload 
The solution for achieving intended preload in bolted connections is theoretically easy if you can measure the effective tension during tightening, for example by strain gauges. Unfortunately the parts of structures prevent direct measurement of axial load. In most practical cases only the bolt head is accessible for measurement and inspection. For this reason, the possibility of accurate measurement of bolt load is significantly limited. In this paper, a new Bolt Head Deflection Indicating (BHDI) method is proposed that utilizes the relation between bolt load and deformation of bolt head. Because this method enables direct indication of bolt load, first the best known direct tension indicating methods and procedures will be overviewed in order to serve as basis for comparison. After that, we present the basic considerations of the proposed BHDI method applying a M12 bolt. The relation between bolt load and bolt head deformation is studied with particular regard to the measurability of the order of deformation magnitude and linearity. Applicability of the proposed BHDI method will be confirmed by analytical estimation, FEA calculations and measurements. At last results of investigation and areas of further work is discussed.

\section{Literature Review}

Regarding the importance of the topic, several means and methods have been developed to measure or indicate preload of bolts. As the proposed BHDI method presented in this paper is nearly related to tension indicator methods, they are summarized briefly in this section for comparison. Hereinafter load indicating washers and special load indicating bolts, as well as ultrasonic measurements, speckle pattern interferometry and optical digital imaging correlation methods will be discussed (Figure 1).

Figure 1.Various Indicating Methods and Means

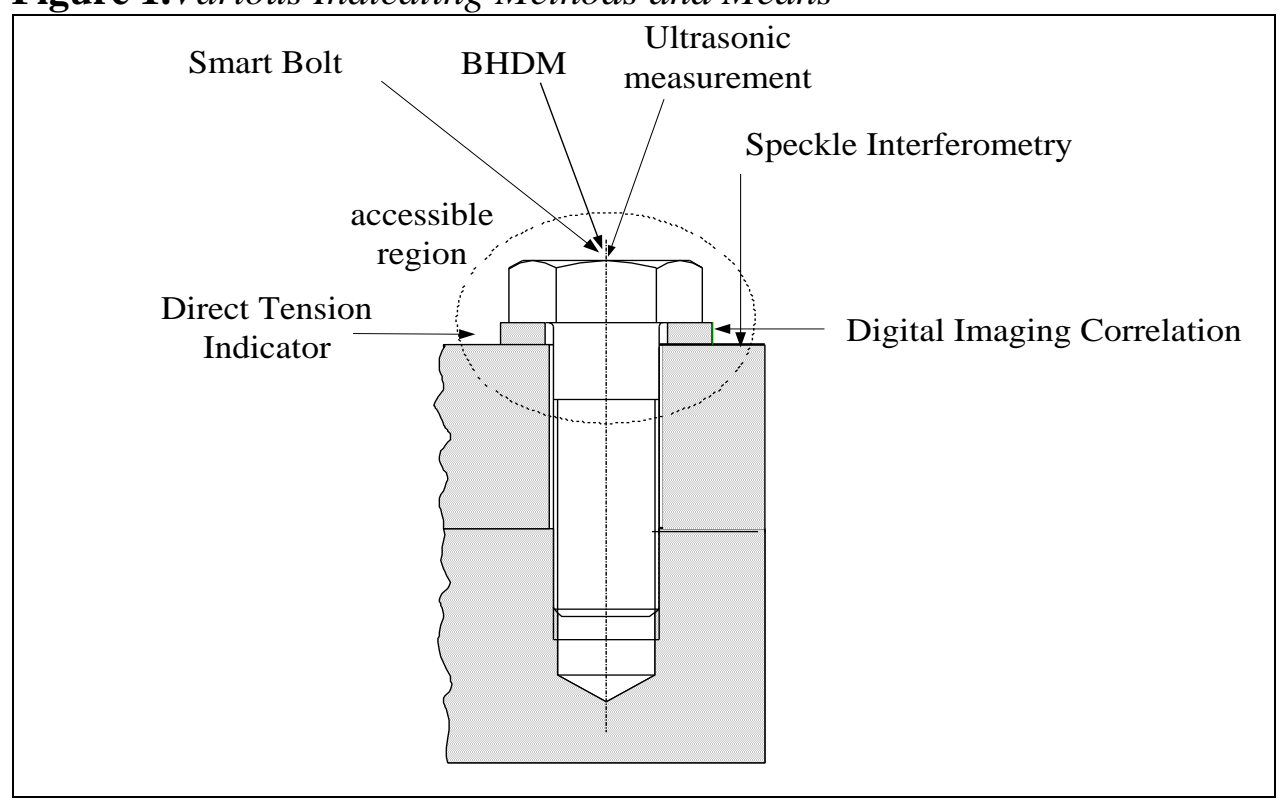




\section{Direct Tension Indicator}

Direct Tension Indicator (DTI) is virtually a special washer put under the bolt head or nut (Figure 2). It has arch-like protrusions that act like small springs, whose compression can be seen even by the eye (Cleary et al., 2012). By inserting a feeler gage in the small gap left by the flattened arches one can measure the distance between the bolt head and washer more precisely. The correct preload is reached when the predetermined gap is achieved between the washer and underhead of the bolt. DTI measures the real bolttension regardless of disturbing or unknown factors. An obvious disadvantage of this method is the limited accuracy of tension measurement.

Figure 2. Direct Tension Indicator

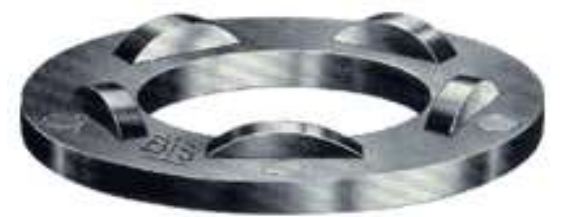

Source: TurnaSure, 2017.

As "bumps" suffer plastic deformation, loss of preload cannot be measured with this method. The greatest advantage of DTI is its simplicity therefore it is widely used in civil engineering.

\section{Special Bolts}

These bolts are designed to be able to indicate axial force in the bolt. One of these bolts is Smart Bolt (Figure 3) that applies the load - elongation relationship (Smart Bolts, 2017). As a bolt is tightened, it changes its length proportionally to the applied load. A built-in visual tension indicator system correlates tension with color: reaching the proper load the color of indicator turns from red to black. This solution provides an accuracy of $+/-5 \%$ on measurements and can be appliedin case of relatively long bolts where elongation is considerable. Another solution is called HiBolt that uses a pin located in a central hole of the bolt (Zhang and Wang, 2012). As a bolt is tightened, the diameter of the hole decreases due to the slight contraction and the pin is gripped. When the correct preload is reached, the pin is locked. Another special solution is PiezoBolt (Consenses, 2017), that looks like a conventional machine bolt with a piezo sensor embedded in the bolt shaft and a pin connection in the head area (Figure 4). During tightening the cable connection unit cannot be attached to the bolt, consequently preload can be measured just after completion of tightening process. Beneficial feature of all the mentioned special bolts is their capability of indicating loss of preload in the course of time with about $\pm 5 \%$ error, but their weakened cross-section by the hole in the shaft is disadvantageous. 
Figure 3. Smart Bolt

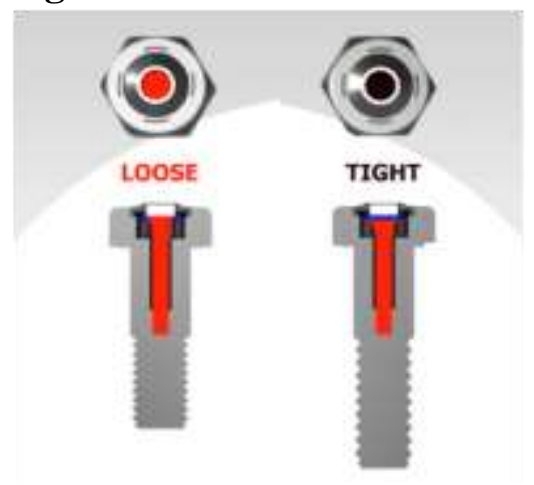

Source: SmartBolt, 2017.

Figure 4. PiezoBolt

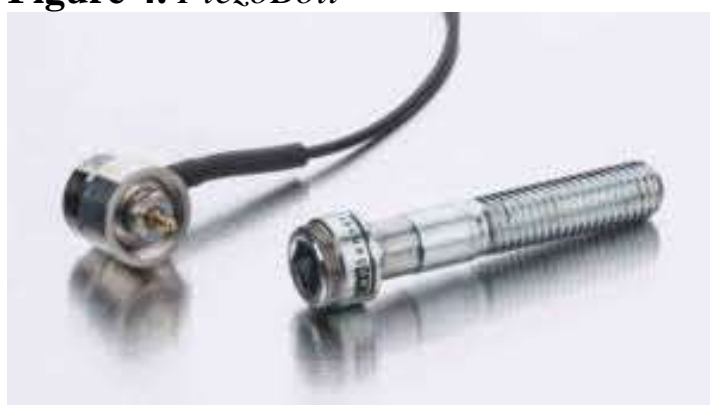

Source: Consenses, 2017.

\section{Optical Methods}

Electronic speckle pattern interferometry (ESPI) technique monitors the strain field in the joint assembly around the bolt (Figure 5) establishing a reliable correlation with the load (Nassar and Meng, 2007; Yang and Ettemayer, 2003). Because deformation of parts of assembly is independent of the friction factor, the direct monitoring of deformation and strain field caused by the load would provide a more reliable indication method of the preload as compared to the conventional torque control method. This ESPI technique is recommended for monitoring the proper tightening of critical bolted structures such as pressure vessels in nuclear power industry. It is to be noted that this method demands very stringent environmental stability and hence cannot be applied in a manufacturing environment. Optical digital imaging correlation method (DIC) was proposed to measure strain in a washer (Huang et al., 2009). It utilizes awasher with white light speckle pattern on its face as an optical transducer (Figure 6). It measures the strain of the washer by automatic digital image correlation, enabling real-time monitoring of clamped force during tightening. The strain measurement happens only in one small angular segment of the washer consequently it is not suitable for small washers. 
Figure 5. ESPI Pattern in the Vicinity of the Bolt (Top View)

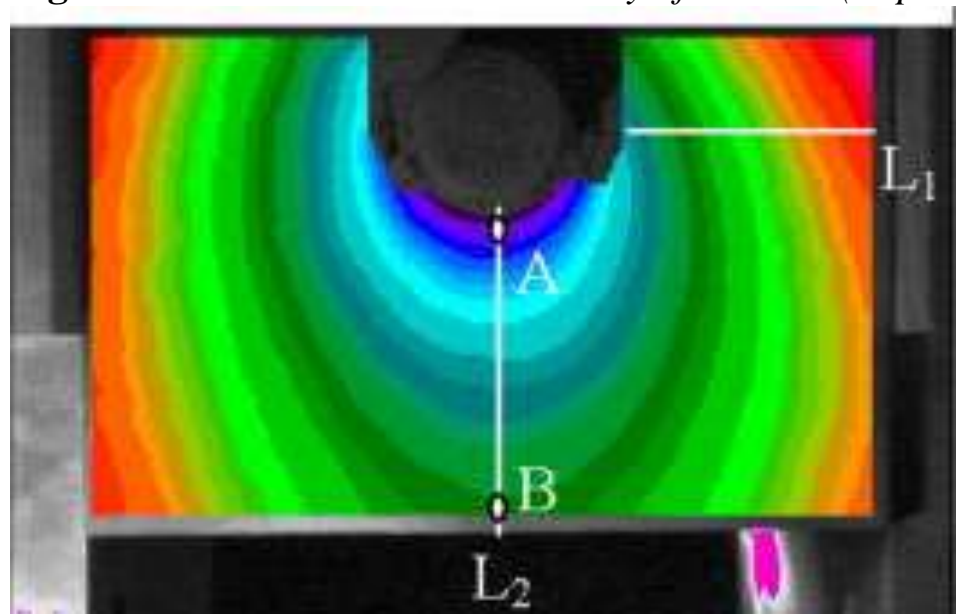

Source: Nassar and Meng, 2007.

Figure 6. Washer as an Optical Force Transducer

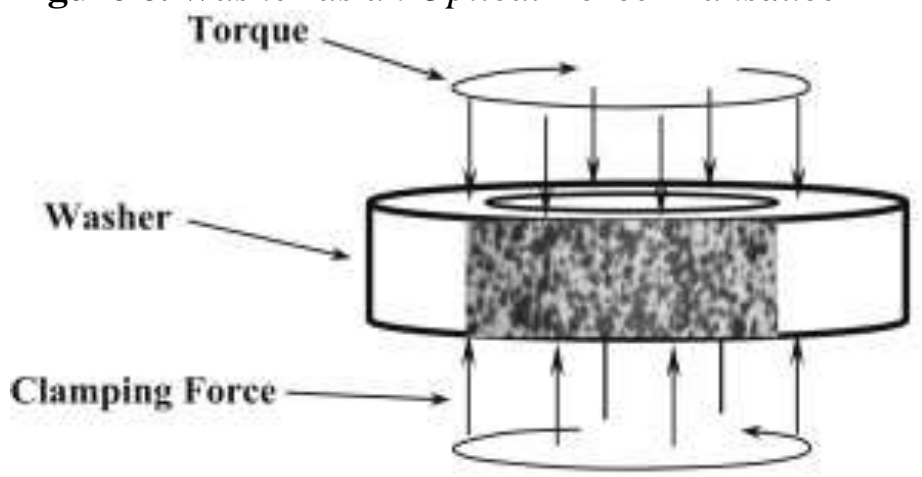

Source: Huang et al., 2009.

\section{Ultrasonic Measurements}

An ultrasonic method is a valuable method to measure bolt load, which is based on the acoustoelastic effect that the velocity of the ultrasonic wave propogated along the bolt depends on the axial stress. The Time-of-Flight Method (TOF) applies an ultrasonic probe set on the bolt head that produces 5$10 \mathrm{MHz}$ ultrasonic waves and measures the variation of transit time due to bolt elongation and change of ultrasonic wave velocity (David and Cheeke, 2002). Two measurements are necessary: one in unloaded situation and another one under load that limits applicability of this method. The variation of ultrasonic velocity due to actual stress in the bolt is very small, therefore data acquisition process requires high sampling rate. This method can be applied for long bolts with surface finished ends with about $\pm 10 \%$ accuracy. In case of smaller bolts environmental disturbances or operator induced errors may affect accuracy of measurement unfavorably. For the precise TOF measurement phase detection method (Jhang et al., 2006; Jesse 2010) can be applied instead of the pulseecho technique. For previously fastened bolts in a structure it is impossible to measure the TOF in unstressed condition. In this situation the Velocity Ratio 
Method can be applied that uses the difference in the acoustoelastic coefficients of longitudinal and transverse waves. The axial load is calculated from the ratio of TOFs in the stressed state only (Johnson et al., 1986, Chaki et al., 2007). Another possibility is applying Mechanical Resonance Frequency Shift Method that is based on the simple one-dimensional resonator model. The resonant frequency of the bolt changes due to its stress induced elongation and change in sound velocity. The deviation of resonant frequency from the resonant frequency in unstressed state is a linear function of the applied stress (Conradi et al., 1974; Heyman, 1977). The mentioned acoustoelastic methods are sensitive to environmental noise and require high cost data acquisition systems that hinder their application in the field.

Another similar procedure is the Piezoelectric Active Sensing Method that applies the fact that surface roughness and area of contact surfaces may change with clamping force. The applied torque on the bolt changes the stiffness, damping and size of the contact areas of bolted assembly. This attenuation based method is based on the damping of ultrasonic waves across the bolted joint (Ritdumrongkul et al., 2003; Yang and Chang, 2006; Wang et al., 2013). Two PZT patches are bonded to different sides of the bolted connection. One PZT is used to generate stress wave that propagates across the connecting surfaces, and the other PZT is used to detect the wave signal. The bolt load can be estimated by measuring the transmitted wave energy. This principle is applied in a smart washer composed of two discs with convex and concave contacting surfaces (Yin, 2016). Two piezoelectric patches are bonded on the non-contacting surfaces of the washer, one of them serves as an emitter and the other is the sensor. The wave energy propagated through the contact surface is proportional to the bolt load.

Piezoelectric Impedance Method can also be applied to structural health monitoring (Liang et al., 1994; Park et al., 2001; Bhalla and Soh, 2003). In this procedure, a piezoceramic patch is bonded to the bolt head and excited by a kilohertz range sweep signal. The patch acts as an actuator as a sensor as well. The vibrating patch transfers its vibration to the structure and it reacts to the electrical circuit. The change of impedance of the electromechanical system due to load level can be measured by precision impedance analyzer.

\section{Methodology}

All of the methods described previously have numerous beneficial features but drawbacks too. It is difficult to compare them because they differ from each other in point of goal, complexity, accuracy and cost. Some of them can provide information about the concrete bolt load, while others can just indicate some change in the loosening of bolted connections. This paper proposed to investigate the opportunity of a simple and cost efficient method capable of directly indicate the bolt preload without complex measuring system. Authors of this paper have the assumption, that may be correlation between bolt load and deformation of bolt head, as well as this deformation can be measured 
accurately. The uppermost, initially plain surface of bolt head may become concave while tightening. Assuming that there is definite relationship between load and deformation of bolt head face, this principle could be applied in practice. In the course of investigation first the existence of the mentioned relationship will be investigated, after that side effects of the bolt head deformation will be calculated applying FEA, and at last surface profiler and Eddy-current displacement measurements will be performed to verify results. Finally, suggestions will be presented on how to indicate bolt head deflection.

\section{Analytical Estimation}

Firstly, it is advisable to find out the expected order of magnitude of the maximum deflection of bolt head in order to check its measurability. The simplest way to offer itself is a quick analytical calculation. Considering the bolt head as a plate loaded by uniformly distributed load, the maximum deflection can be calculated (Figure 7).

Figure 7.Model for Analytical Estimation

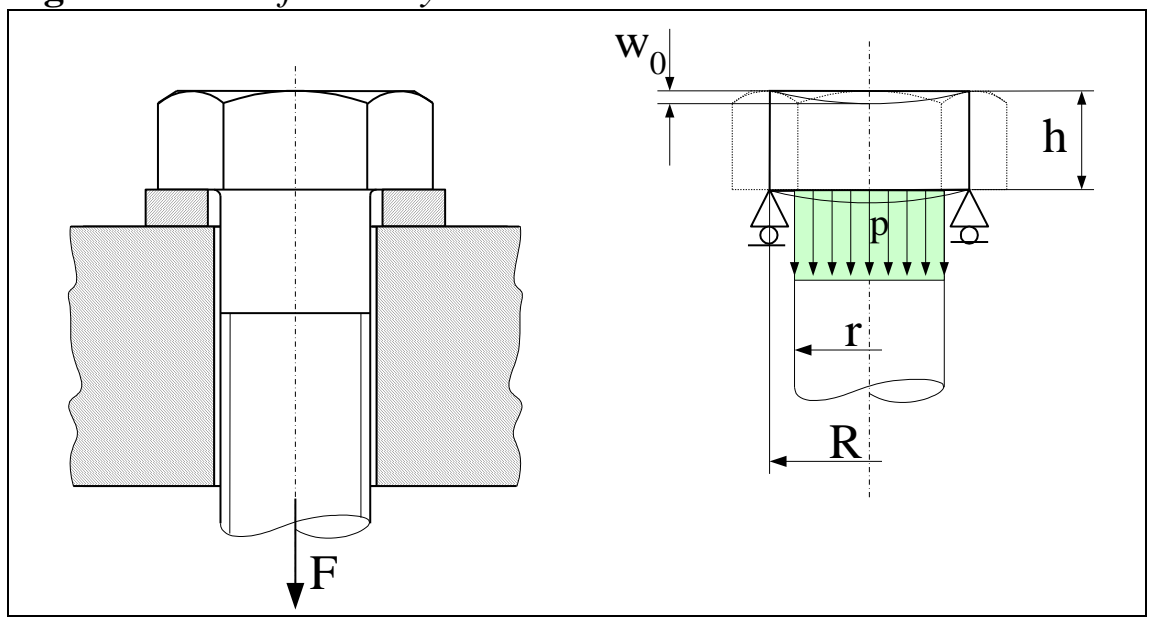

It is to be noted, that assumptions of this approach exist only partly, because the thickness of plate (bolt head height) is not small enough compared to its lateral dimensions. However, for want of better we apply the differential equation (1) of circular plates with axially symmetric load (Timoshenko and Goodier, 1970) such as:

$$
\left(\frac{\partial^{2}}{\partial \mathrm{r}^{2}}+\frac{1}{\mathrm{r}} \frac{\partial}{\partial \mathrm{r}}\right)\left(\frac{\partial^{2}}{\partial \mathrm{r}^{2}}+\frac{1}{\mathrm{r}} \frac{\partial}{\partial \mathrm{r}}\right) \mathrm{w}=\frac{\mathrm{p}(\mathrm{r})}{\mathrm{K}}
$$

Where:

$\mathrm{K}=\frac{\mathrm{Eh}^{3}}{12\left(1-v^{2}\right)}$ is the bending stiffness of the plate and $v$ is the Poisson's ratio. Deriving equation (2) for the case of simple circular support of radius $R$ and 
uniformly distributed load $p$ inside a circular area of radius $r$, the maximum deflection yields

$$
\mathrm{w}_{\text {max }}=\frac{\mathrm{pr}^{4}}{\mathrm{Eh}^{3}}\left[1.733\left(\frac{\mathrm{R}}{\mathrm{r}}\right)^{2}-1.037-0.683 \ln \left(\frac{\mathrm{R}}{\mathrm{r}}\right)\right]
$$

Data of the investigated M12 bolt of material class 8.8 are as follows: radius of loaded area $r=6 \mathrm{~mm}$, inner radius of washer $r_{w}=7 \mathrm{~mm}$, maximum load $\mathrm{F}=40 \mathrm{kN}$, maximum normal stress $\mathrm{p}=354 \mathrm{~N} / \mathrm{mm}^{2}$, Young's modulus $\mathrm{E}=2.1 \cdot 10^{5}$ $\mathrm{N} / \mathrm{mm}^{2}$, height of bolt head $\mathrm{h}=8 \mathrm{~mm}$. The greatest source of errors of this formula is the effective radius of the contact area of bolt head and washer. In absence of information about the radius of the support you may assume that the radius of support is identical to the inner radius of the washer, hence let us assume $\mathrm{R}=7 \mathrm{~mm}$. According to this conservative estimation you may expect $\mathrm{w}_{\max }=0.0052 \mathrm{~mm}=5.2 \mu \mathrm{m}$ maximum deflection, which means a tiny amount of deformation, but it can be measured with a feasibly chosen instrument. It is to be noted that a M12 bolt of material class 8.8 can bear somewhat higher pure tension of $40 \mathrm{kN}$, but bolt shaft suffers generally torsion as well. The combination of normal and shear stresses must not exceed yield stress.

\section{Finite Element Analysis}

A more reliable result of bolt head deflection can be achieved by applying FEA. This approach can take into consideration the contact between bearing surfaces, as well as the real load distribution inside the bolt head. In this study Abaqus6.11 software is applied. Between contacting surfaces tie contact is defined. Modeling the case of bolt head deformation, it is not necessary to deal with marginal issues. For example the load in the screw shaft may be regarded evenly distributed, because the nut is far enough from the head and according to Saint Venant's principle its effect is negligible (Figure 8).

Figure 8. Mesh and Load of the Bolt

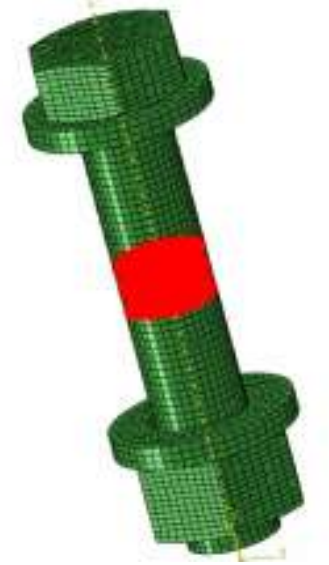


For the same reason the effect of stress concentration close to threads is also neglected. The fastened plate is chosen deliberately thick and stiff in order not to affect results considerably. These assumptions make it possible applying simpler geometrical model with less elements that enables you to concentrate only on the washer-bolt head interaction. For the sake of simplicity, first a bolt with a centric washer was investigated. The load of the bolt was a pure tensile force of $40 \mathrm{kN}$, while torsion was omitted. Knowing that after tightening high amount of torsion moment is also present in the bolt shaft, you may assume, that it slightly affects the out of plane deformation of the bolt head. The mesh contained first order hexahedron and penta elements with total number of 17248. From this bolt head contained 10896 hexa and 564 penta elements with average length of $0.94 \mathrm{~mm}$. Standard Bolt Load module was applied to define tensile load. Simulation took about one minute with a dual core processor. The $\mathrm{y}$-directional deflection of bolt head under $40 \mathrm{kN}$ load can be seen in Figure 9.

\section{Figure 9. Bolt Head Deflection}

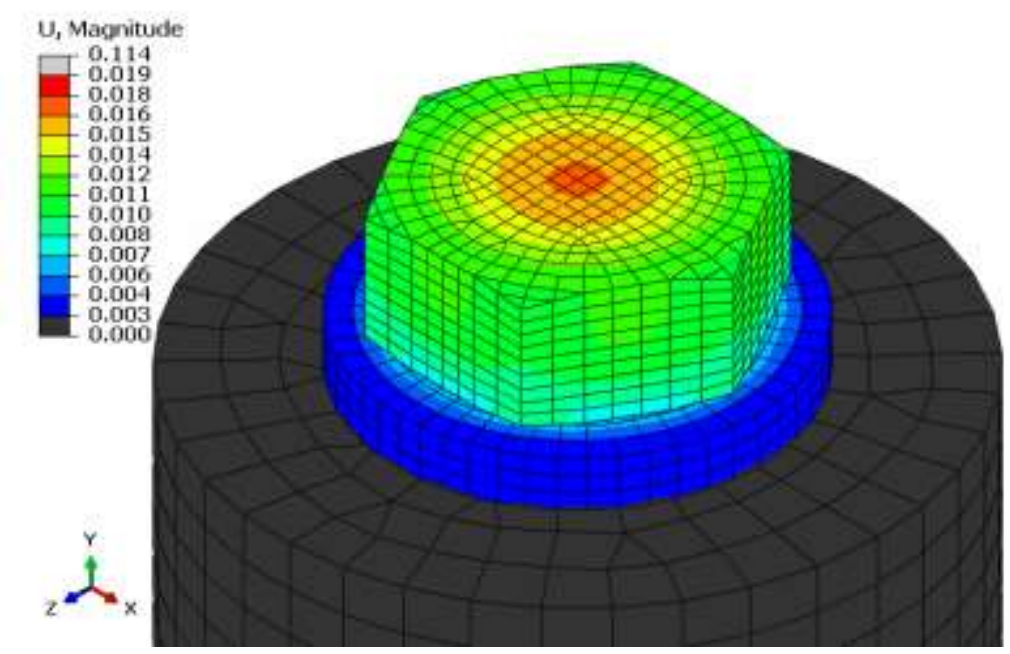

Figure 10 depicts the same deflection field near the bolt head surface in cutaway view.

Figure 10. Deflection in the Cross-section of the Bolt Head

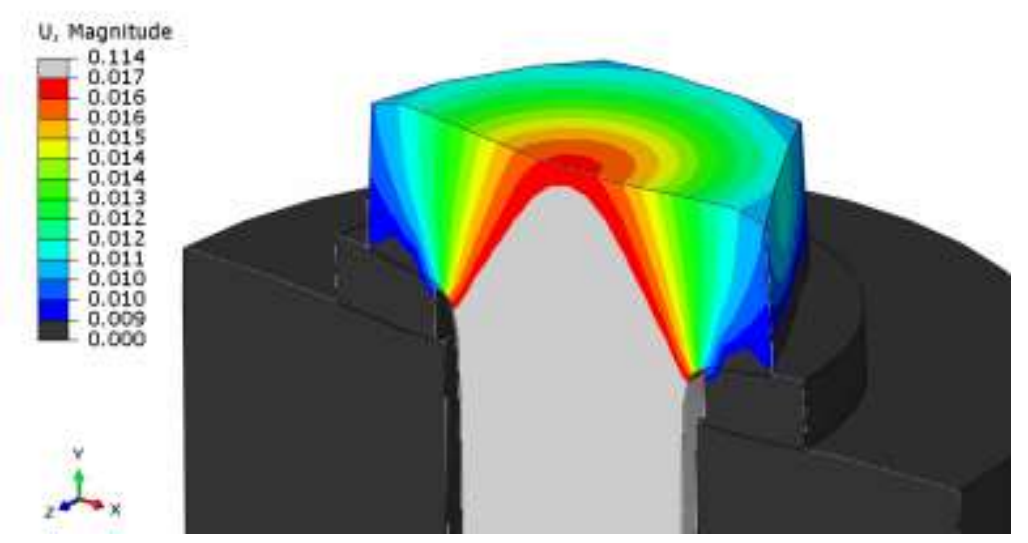


Deflection of bolt head surface in direction " $y$ " was calculated in four points $1 \ldots 4$ of the $\mathrm{x}$-axis by Abaqus (Figure 11). The distance among evaluation points was chosen to $3 \mathrm{~mm}$.

Figure 11. Evaluation Points

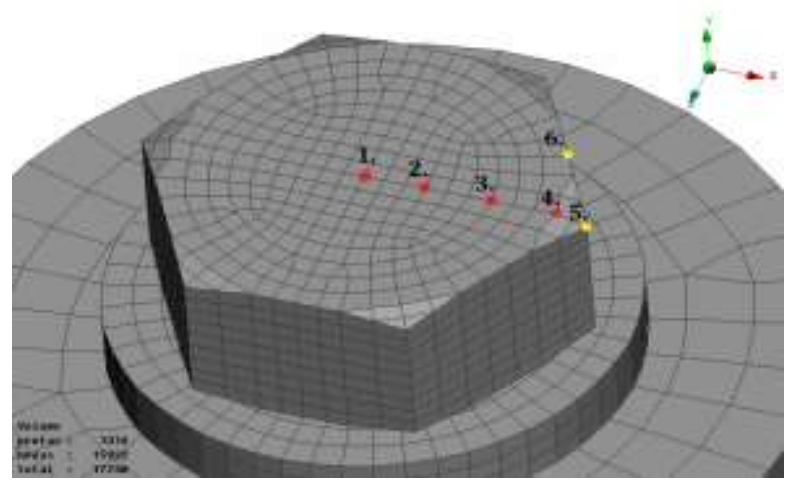

In the course of loading all points of bolt head move relative to the base plate. In order to find the deformation of the upper surface of bolt head, we needed to calculate the deflections of evaluation points relative to each other. In Figure 12 , the y-directional deflections of evaluation points 1,2 and 3 of relative to that of point 4 are depicted highly magnified. The initially plain upper surface became concave as expected before. Calculations were performed in two load levels, $20 \mathrm{kN}$ and $40 \mathrm{kN}$ respectively. In case of axially symmetric arrangement and load the deflection curves are evidently symmetric. The maximum relative deflection of center point 1 at $40 \mathrm{kN}$ load is exactly the double that of $20 \mathrm{kN}$ load, that means, that deflection of center point relative to the head edge is directly proportional to the applied axial load. This finding is an important result, because it makes the basis of the proposed method. It is also interesting to note, that deflection results of the more sophisticated FEA method are very similar to that of the analytical estimation performed earlier.

Figure 12. Deflection of Evaluation Points 1 ...4

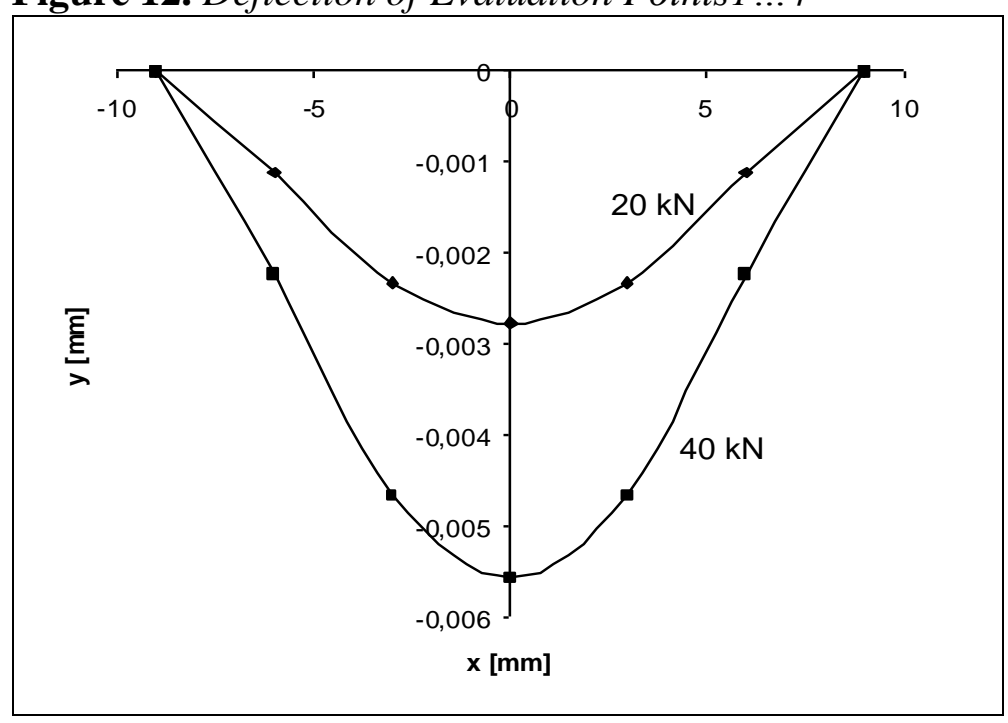


As a second step additional torsion was included beside tension. Residual torsion is always present in the bolt shaft due to self-locking of threads. The torque was calculated with 0.12 friction coefficient. As expected, calculation with additional torsion did not show any difference, i.e. bolt overhead deflection is virtually independent of torsion.

Another interesting issue is the bolt location in the bore. Because the bore diameter is always higher than that of the bolt shaft, bolt can take up eccentric position in the bore. It is a similar situation when an eccentrically located washer is applied under the bolt head. These circumstances cannot be avoided in practice, thus this problem is to be investigated. We calculated the deflection of the bolt head in case of an eccentrically placed washer with $0.8 \mathrm{~mm}$ eccentricity in the x-direction. The results are depicted in Figure 13. Several curiosities are noticeable: the originally horizontal plane of the bolt surface turned away a bit, one of the terminal points moved $1.2 \mu \mathrm{m}$ less than the another one. The locus of the maximum deflection shifted to the right with about $2 \mathrm{~mm}$. As a consequence the centric deflection decreased to about $4.8 \mu \mathrm{m}$, while the maximum deflection remained nearly the same $(5.8 \mu \mathrm{m})$ as in case of centrally placed washer. These observations have importance and are to be taken into consideration when designing the sensor/indicator unit.

Figure 13. Eccentric Washer Location

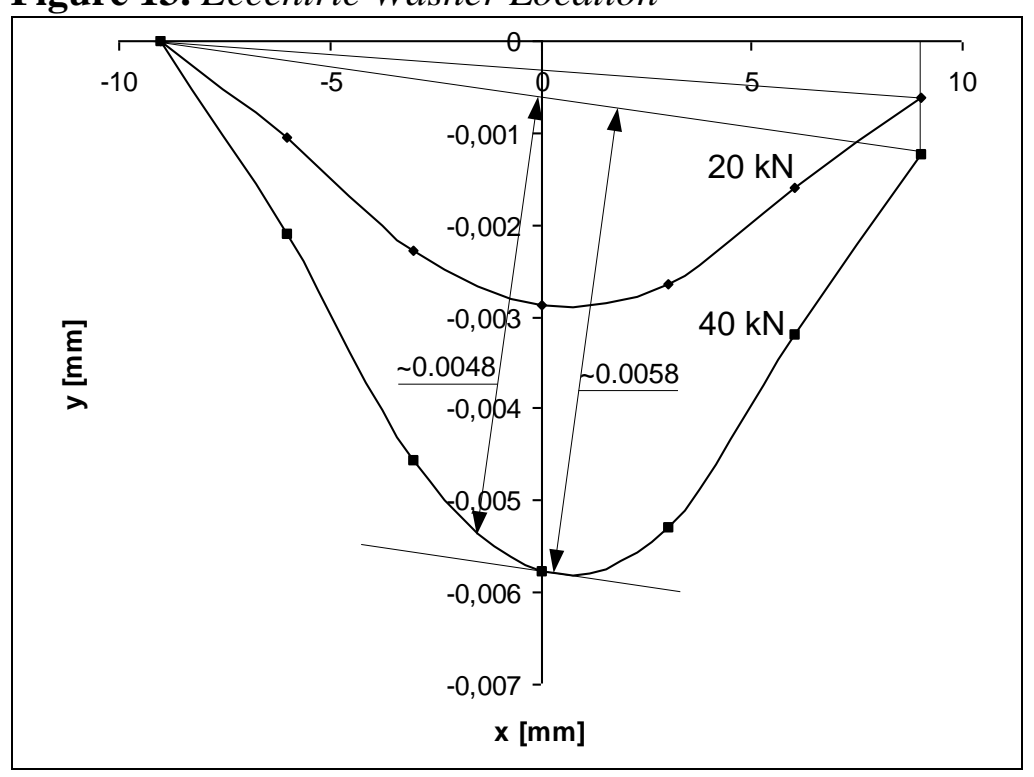

\section{Measurements}

Results gained by FEA method has been verified by two different types of measurements. The first one could be applied in laboratory conditions and it was done with a surface profiler. The second one was intended for industrial environment and it was performed by means of an Eddy-current sensor. The tested configuration was the same in both cases: it consisted of a bolt to be measured, a washer between the bolt head and plate, a pancake-type force sensor Hottinger-Baldvin KMR-100, an axial ball bearing to remove torsion in 
bolt shaft and protect the load cell as well as a nut (Figure 14). The difficulty of measurement lies in the fact that all the points of the bolt head deform. Technically only relative deflection of point 1 relative to point 4 of head is of essential importance.

Figure 14. The Tested Configuration

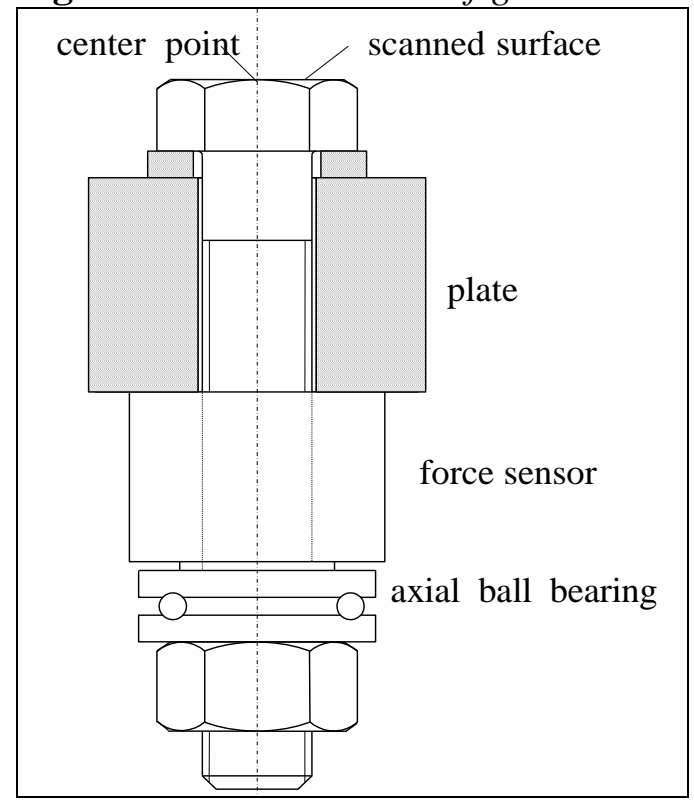

\section{$\underline{\text { Surface Profiler Measurement }}$}

First the out-of-plane deformation of the bolt head was measured by a Taylor Hobson Talysurf CLI 2000 optical surface profiler (Figure 15).

Figure 15.Testing the Initial Shape of the Surface

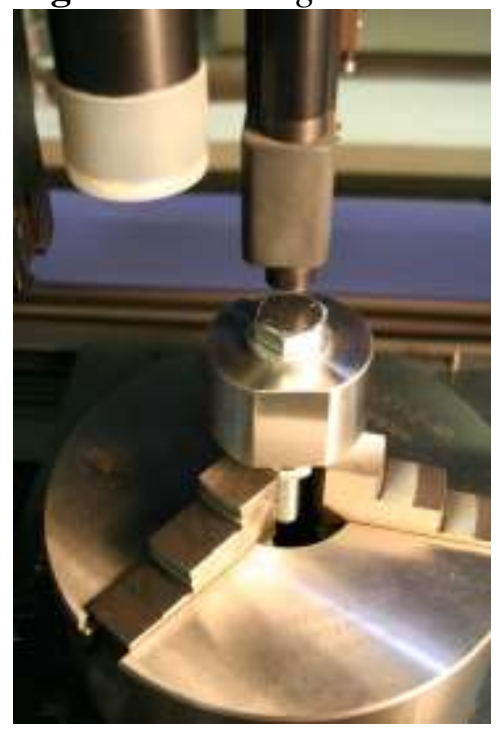


It is obvious that in manufacturing environment this type of measurement cannot be applied, but in research phase it is quite appropriate. In order to eliminate disturbing effect of initial surface imperfections the bolt head had been polished. The preloaded bolt was chucked in a holder and was scanned over a line of length $16 \mathrm{~mm}$. This process was repeated after each load stages. In the process of setting a new load level the bolt had to be taken out of the holder and put in again, while unfortunately we could not ensure the fully identical position of the bolt relative to the scanning direction. However, the symmetric shape and deformation pattern of the bolt minimized this kind of error. Scanning was performed by velocity of $50 \mu \mathrm{m} / \mathrm{s}$ and point densities of $0.5 \mu \mathrm{m}$. Over the scanned region, 32000 points were evaluated. The blue curve depicts the deflection, the red one is an approximating circle. The results of measurements before and after loading by a force of $40 \mathrm{kN}$ can be seen in Figure 16. It is interesting to notice that the bolt head surface had some convexity in its initial state. Commercial, unpolished bolts may have probably much higher shape intolerances. Comparing the figures you can notice that the bolt's initial convex surface (Figure 16a) turned concave after loading (Figure 16b). The deflection of the center point was calculated as the difference of the final and initial deflections.

In case of preload of $40 \mathrm{kN}$ the resulting deflection was $4.1-(-2.8)=6.9$ $\mu \mathrm{m}$ that is somewhat higher than the value gained by FEA.

Figure 16. Surface Contour a) Before and b) After Loading

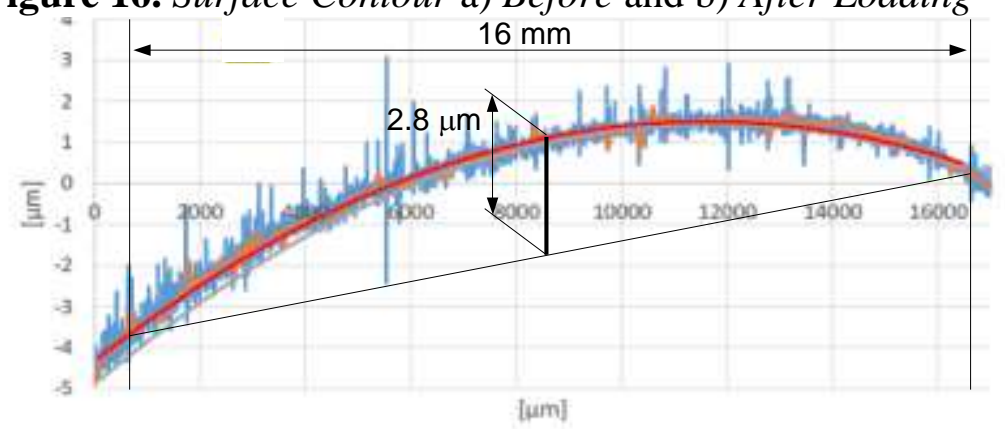

a) before loading

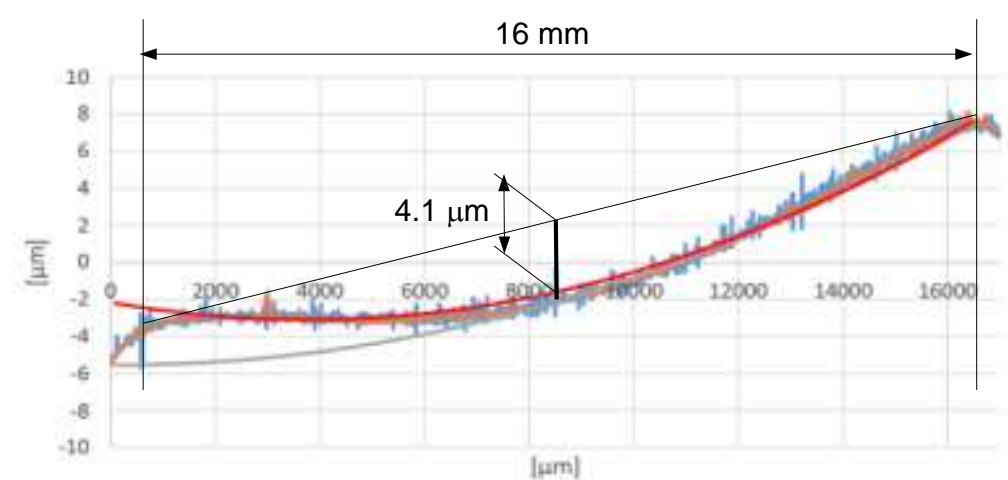

b) after loading 


\section{$\underline{\text { Eddy-Current Measurement }}$}

The second method was intended to prove measurability of such tiny deflections in practice. Fortunately, you need to know only the displacement of a single point, namely the center of the bolt head relative to the head edge. In this case, a reasonable solution is applying an Eddy-current sensor. To eliminate dislocation errors between bolt head and sensor during setting various loads, the sensor probe has been attached to a non-conductive plastic cap that was glued to the bolt head (Figure 17).

Figure 17. Attaching the Eddy-Current Sensor

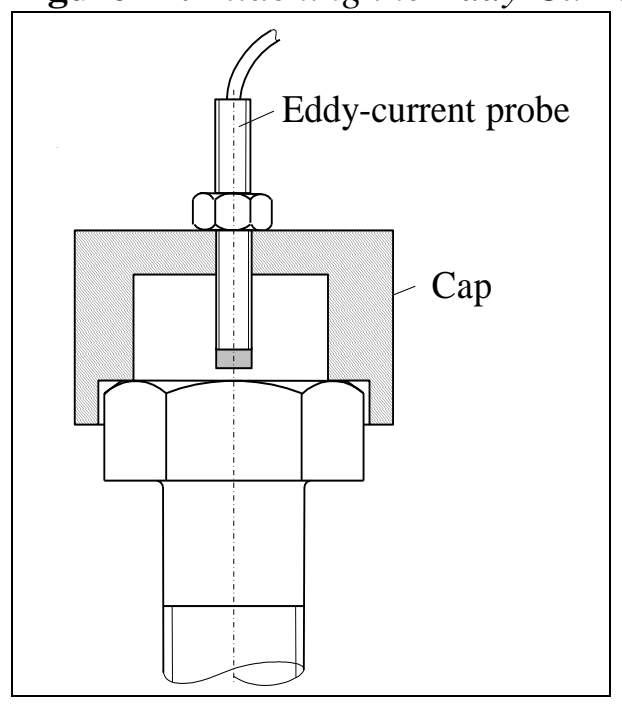

The output range of the applied TX2 Eddy-current sensor was between 0 and $10 \mathrm{~V}$ in the measuring range of $0.5 \mathrm{~mm}$ but its characteristics is somewhat nonlinear. In this experiment, only the measurability of deflection was checked therefore we did not have to calibrate the sensor. The measured output voltage of the sensor versus force relationship can be seen in Figure 18.

Figure 18. Output Voltage of Eddy-current Sensor versus Bolt Load

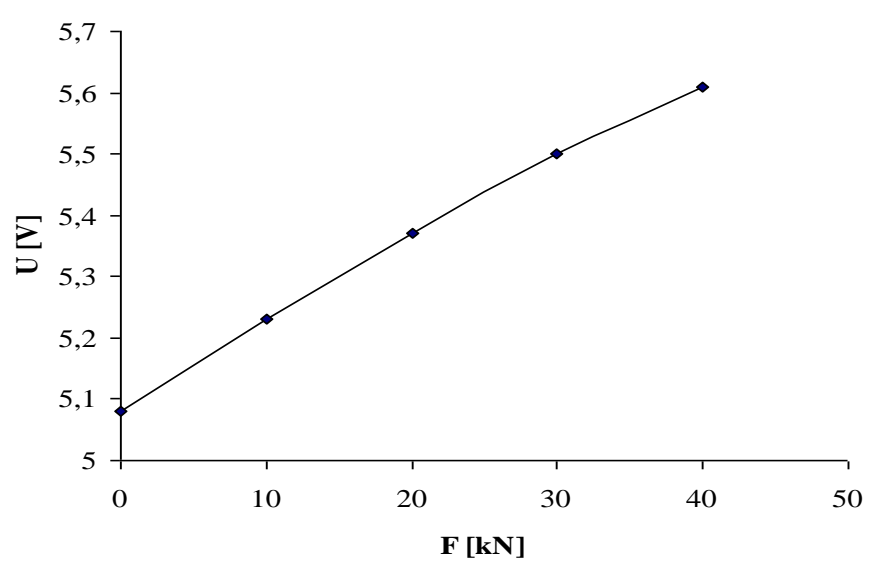


You can see that deflection of the bolt head is measurable without difficulty. The initial slope of the curve or in other words the sensibility of the measurement is about $0.01 \mathrm{mV} / \mathrm{N}$. Applying a voltmeter of $1 \mathrm{mV}$ resolution, preload can be determined with $100 \mathrm{~N}$ resolution. Assuming an intended preload of $40 \mathrm{kN}$ the bolt preload can be measured with $0.25 \%$ accuracy in laboratory conditions. It is obvious, that the sensor output is nearly proportional to the applied bolt load. The slight nonlinearity can be attributed to both the nonlinear characteristics of the Eddy-current sensor and the elastic-plastic behavior of bolt material.

\section{Discussion}

Analytical estimation and finite element analysis as well as both measurements confirmed the preliminary assumption of authors that bolt head face deflection is nearly proportional to the bolt load. The deflection of the bolt head is measurable in case of even a rather small M12 bolt at moderate proof load. This phenomenon - as a theoretical basis - can be applied for indicating effective bolt load but its industrial application raises many questions to be answered. The presented method is applicable primarily for monitoring bolt load during tightening process. Measurement of the preload in case of previously tightened bolts is difficult because thickness of rust, dust and dirt deposited in the meantime on the bolt surface is in the order of magnitude of deflection to be measured. Besides there isn't reliable information on the initial shape of all bolts previously tightened, because as seen before, even a finished bolt surface may have flatness errors (concave or convex features). It is also difficult to ensure the same sensor position that was applied in the past. During tightening, the rotating wrench exerts lateral forces onto the sides of the bolt head that may slightly affect overhead deflection too. Hence, at the moment of measurements the bolt should be stationary to avoid this kind of side effects. In the future further investigations may ascertain the extent of this effect. In this early stage of investigation there are several open questions to be answered. Some of them are associated with theoretical issues, others relate to measurement ones. As for theoretical field, calculations by finite element analysis are needed to clear effects of dimensions and stiffness of assembly parts onto the bolt head deformation. Effects of geometrical imperfections such as tolerances of dimensions, eccentric placement of washer, non-perpendicularity of bolt head and so on are to be investigated as well. As seen before, in case of an eccentric washer the deflection profile was asymmetric. A centrally located Eddy-current sensor cannot be able to measure the accurate value of central point deflection. Application more than one sensors may solve this problem.

In mass production, it is not necessary to apply bolts with high surface quality and flatness. In turn, the proposed measuring method requires good fit between bolt head and sensor holder. Another problem area is attaching sensor holder to bolt head securely during tightening. As the range of the expected bolt head deflection is under $10 \mu \mathrm{m}$ in case of a screw of medium size, no relative motion is permitted between bolt and sensor holder during measurement. 
Also, centered position of the sensorshould be secured in order to achieve clear boundary conditions of measurement. In the same time sensor unit should not hinder attachment of wrench onto the bolt head. It is to be explained the tolerable flatness and surface roughness of bolt head that guarantees good fit of bolt head and sensor holder. It must also be elaborated an equipment attaching the sensor holder to the bolt head reliably during tightening. A further challenge is to integrate the sensor into a torque wrench. The last requirement is to solve sensor output signal transmission to a stationary signal conditioning unit from the sensor attached to the rotating bolt. Problem areas mentioned before need more detailed investigations but they are out of scope of this paper. As for future works, instead of applying a complicated measuring system a viable solution could be using brittle coating on the bolt head at normal temperatures (Dally and Riley, 1991). This thin and cheap coating can be applied on the bolt head without surface polishing. The shape and extent of crack pattern of lacquer could be easily evaluated, but in absence of experiments accuracy of load measurement is still unknown. The only disadvantage of this solution is that loss of preload cannot be indicated, because cracks formed previously at higher loads could not leave off at lower loads.

\section{Conclusions}

This paper presented the concept of a new nondestructive measuring method of bolt preload. The examined M12 bolt head face deflection has been determined analytically, by means of FEA as well as Eddy-current and surface profile measurements. It can be stated that deflection of bolt head center is fairly proportional to the preload of bolt and independent of friction effects. The effect of eccentric placement of washer was also investigated. It turned out that eccentric position of washer affects only the locus of the maximum deflection while its value is independent of the eccentricity. This method can be applied basically during tightening process of bolted structures. This finding is inspiring to deal with this idea in more detail. Hopefully, after solving additional problems, this method may be applied industrially in the future.

\section{Acknowledgments}

This paper has been co-financed by the European Union and the Hungarian Government under the EFOP-3.6.1-16-2016-00017 project.

\section{References}

Bhalla, S. and Soh, C. K. 2003. Structural impedance based damage diagnosis by piezotransducers. Earthquake Engineering Structural Dynamics. Vol. 32, Iss.12, p. 18971916.

Bolt Science. Methods of Tightening Threaded Fasteners.http:/www.boltscience.com/ pages/tighten.htm. [Downloaded 17/06/2017]. 
Chaki, S., Corneloup, G., Lillamand, I. and Walaszek, H. 2007. Combination of longitudinal and transverse ultrasonic waves for in situ control of the tightening of bolts. Journal of Pressure Vessel Technology. Vol. 129, No. 3, p. 383-390.

Cleary, D. B., Riddell, W. T. and Lacke, C. J. 2012. Effect of washer placement on performance of direct tension indicators with curved protrusions. Engineering Journal AISC.Vol. 49, No. 2. p. 55-63.

Conradi, M. S., Miller, J. G., Heyman, J. S. 1974. A transmission oscillator ultrasonic spectrometer.Review of Scientific Instruments. Vol. 45, No. 3, p. 358-360.

Dally, J. W. and Riley, W. F.1991. Experimental stress analysis.McGraw-Hill/ Education, London.

David, J. and Cheeke, N. 2002.Fundamentals and application of ultrasonic waves. CRC Press, New York.

Fukuoka, T. and Takaki, T. 2004. Evaluations of the tightening process of bolted joint with elastic angle control method. Analysis of Bolted Joints.ASME/JSME Pressure Vessels and Piping Conference, Vol. 478, p.11-18.

Göran, R. T. 2003. Controlled tightening over the yield point of a screw based on Taylor's series expansions. Journal of Pressure Vessel Technology. Vol. 125, No. 4, p. 460-466.

Hesse, T. Ghorashi, M. and Inman, D. J. 2004. Shape memory alloy in tension and compression and its application as clamping force actuator in a bolted joint. Part 2-Modeling. Journal of Intelligent Material Systems and Structures. Vol. 15, No. 8, p. 589-600, DOI:10.1177/1045389X04042791.

Heyman, J. S. 1977. A CW ultrasonic bolt-strain monitor. Experimental Mechanics. Vol. 17, No. 5, p. 183-187.

Huang, Y. H., Liu, L., Yeung, T. W. and Hung, Y. Y. 2009.Real-time monitoring of clamping force of a bolted joint by use of automatic digital image correlation. Optics Laser Technology. Vol. 41, No. 4, p. 408-414.

Jesse, R. M. 2010. Joint integrity monitoring using permanent ultrasonic bolt load transducers.Proceedings of the ASME Power Conference. p. 1-9.

Jhang, K. Y., Quan, H. H., Ha, J. and Kim, N. Y. 2006.Estimation of clamping force in high-tension bolts through ultrasonic velocity measurement. Ultrasonics. Vol. 44, p. 1339-1342.

Johnson, G. C. Holt, A. C. and Cunningham, B. 1986.An ultrasonic method for determining axial stress in bolts. Journal of Testing and Evaluation.Vol. 14, No.5, p. 253-259.

Liang, C., Sun, F. P., Rogers, C. A. 1994. Coupled electro-mechanical analysis of adaptive material system-determination of the actuator power consumption and system energy transfer.Journal of Intelligent Material Systems and Structures. Vol 5, No. 1, p. 12-20.

Nassar, S. A. and Meng, A. D. 2007. Optical monitoring of bolt tightening using 3D electronic speckle pattern interferometry.Journal of pressure Vessel Technology. Vol. 129, no. 1, p. 89-95. DOI:10.1115/1.2389024.

Park, G., Cudney, H. H., Inman, D. J. 2001. Feasibility of using impedance-based damage assessment for pipeline structures. Earthquake Engineering Structural Dynamics. Vol. 30, Iss.10, p.1463-1474.

PiezoBolt. http://consenses.de. [Downloaded 16/04/2017].

Ritdumrongkul, S.,Abe, M., Fujino, Y., Miyashita, T. 2003. Quantitative health monitoring of bolted joints using a piezoceramic actuator \& sensor. Smart Materials and Structures. Vol. 13, p. 20-29.

Sawa, T., Omiya, Y., Takagi, Y. and Torii, H. 2009. Effects of scatter in axial bolt force on the seeling performance of pipe flange connections at elevated temperature. 
Proceedings of the ASME Pressure Vessels and Piping Conference. Vol. 2, p. 139147.

Shoberg, R. Engineering Fundamentals of Threaded Fastener Design and Analysis. PCB Load \& Torque. http:/www.pcbloadtorque.com. [Downloaded: 11/06/2017].

SmartBolts. http:/smartbolts.com. [Downloaded 16/04/2017].

Timoshenko, S.P. and Goodier J. N. 1970. Theory of elasticity. McGraw-Hill, New York.

TunaSure: Bolting Technology \& Direct tension Indicators (DTIs). http:/tunasure. com. [Downloaded 12/05/2017].

Wang, T., Song, G., Liu, S., Li, Y. and Xiao, H. 2013. Review of bolted connection monitoring. International Journal of Distributed Sensor Networks. Article ID 871213.

Yang, L. X. and Ettemayer, A. 2003. Strain measurement by three-dimensional electronic speckle pattern interferometry: potentials, limitations and applications. Optical Engineering. Vol. 43, No. 5, p. 1257-1266. DOI: 10.1117/1.1566781.

Yang, J. and Chang, F. K. 2006.Detection of bolt loosening in C-C composite thermal protection panels: II.Experimental verification.Smart materials and Structures. Vol. 15, No. 2, p. 591-599.

Yin, H. et al. 2016.A Smart Washer for Bolt Looseness Monitoring Based on Piezoelectric Active Sensing Method.Applied Sciences.Vol. 6, No. 11.320. DOI: 10.3390/app6110320.

Zhang, X. and Wang, X. 2012.An Improved Torque Method for Preload Control in Precision Assembly of Miniature Bolt Joints. Strojniskivestric-Journal of Mechanical Engineering. Vol. 58, No.10, p. 578-586. 
